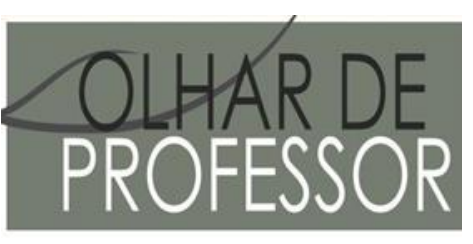

\title{
Emancipação do olhar: o papel da fotografia numa formação escolar reflexiva
}

\author{
Emancipation of the look: the role of photography in a \\ reflective school formation
}

\section{Emancipación de la mirada: el papel de la fotografía en una formación escolar reflexiva}

Guilherme Susin Sirtoli

https://orcid.org/0000-0002-8373-6456

Cláudia Mariza Mattos Brandão²

https://orcid.org/0000-0002-2161-4779

\begin{abstract}
Resumo: Este trabalho discute questões acerca da fotografia enquanto propulsora do pensamento crítico e da formação de sujeitos reflexivos na sociedade contemporânea. Para tal, situa-se a fotografia enquanto fonte de comunicação, sendo considerada uma linguagem não-verbal (FERRARA, 2002), resultante de uma percepção da realidade (DUBOIS, 1993) e de uma criação poética do imaginário (DURAND, 2004). O trabalho analisa atividades desenvolvidas no projeto de extensão "PhotoGraphein vai à Escola" (UFPel), com escolares do ensino fundamental em escolas públicas da região de Pelotas e Rio Grande - RS. As atividades extensionistas atuam com base em experiências estéticas formadoras (DEWEY, 2010) e na relação entre a fotografia e o olhar, possibilitando perspectivar o quanto tais questões reverberam no âmbito do ensino em Artes Visuais. Com tal análise foi possível perceber relações estabelecidas e aprendizados que alteraram positivamente a forma com que os jovens educandos decodificam e percebem os símbolos presentes no mundo ao redor, possibilitando a transformação do vivido em experiências formadoras para todos os envolvidos.
\end{abstract}

Palavras-chave: Artes Visuais. Educação. Fotografia. Experiência. Ensino básico.

Abstract: This article discusses questions about photography as a driver of critical thinking and the formation of reflective subjects in contemporary society. To this end, photography is situated as a source of communication, being considered a non-verbal language (FERRARA, 2002), resulting from a perception of reality (DUBOIS, 1993) and a poetic creation of the imaginary (DURAND, 2004). The work analyzes activities developed in the extension project "PhotoGraphein vai à Escola" (UFPel), with elementary school students in public schools in the region of

\footnotetext{
I Especialista em Artes (UFPel). Professor de Artes atuando no Magistério Público Estadual do Rio Grande do Sul (SEDUC/RS). E-mail: guisusinsirtoli@gmail.com.

2 Doutora em Educação (UFPel). Professora do Centro de Artes, atuando no Artes Visuais - Licenciatura e no Programa de Pós-Graduação (Mestrado) em Artes Visuais da Universidade Federal de Pelotas/UFPel. E-mail: claummattos@gmail.com.
}

Olhar de professor, Ponta Grossa, v. 25, p. I-18, e-1755I.013, 2022.

Disponível em <https://revistas2.uepg.br/index.php/olhardeprofessor> 
Pelotas and Rio Grande - RS. The extension activities work based on forming aesthetic experiences (DEWEY, 2010) and the relationship between photography and the look, making it possible to envision how much such issues reverberate within the scope of teaching in Visual Arts. With this analysis, it was possible to perceive established relationships and learning that positively altered the way that young students decode and perceive the symbols present in the world around them, enabling the transformation of the lived into forming experiences for all involved.

Keywords: Visual Arts. Education. Photography. Experience. Basic education.

Resumen: Este artículo discute cuestiones sobre la fotografía como motor del pensamiento crítico y la formación de sujetos reflexivos en la sociedad contemporánea. Para ello, la fotografía se sitúa como fuente de comunicación, siendo considerada un lenguaje no verbal (FERRARA, 2002), resultado de una percepción de la realidad (DUBOIS, 1993) y una creación poética del imaginario (DURAND, 2004). El trabajo analiza las actividades desarrolladas en el proyecto de extensión "PhotoGraphein vai à Escola" (UFPel), con alumnos de primaria de escuelas públicas de las ciudades de Pelotas y Rio Grande - RS. Las actividades de extensión operan a partir de experiencias de formación estética (DEWEY, 2010) y en la relación entre fotografía y mirada, permitiendo vislumbrar cómo repercuten estos temas en el ámbito de la enseñanza de Artes Visuales. Con el análisis fue posible percibir relaciones establecidas y aprendizajes que cambiaron positivamente la forma en que los jóvenes estudiantes decodifican y perciben los símbolos presentes en el mundo, posibilitando transformar lo vivido en experiencias formadoras para todos los involucrados.

Palabras-clave: Artes visuales. Educación. Fotografía. Experiencia. Enseñanza básica.

\section{Introdução}

É possível dizer que hoje vivemos em uma “civilização da imagem”, para a qual a fotografia tem um papel preponderante, além da internet e das redes sociais, que também são importantes na formação do espaço urbano contemporâneo. Para muitos indivíduos, as imagens acabam sendo uma espécie de fuga da realidade, pois "Hoje produzimos com a ajuda da mídia digital, imagens em quantidades gigantescas. Também essa produção massiva de imagens pode ser interpretada como uma reação de proteção e fuga” (HAN, 20|8, p. 57).

As sociedades produzem milhares de informações em segundos, transmitidas e distribuídas para todo o globo, sendo que as imagens são preponderantes nesses processos. E tal situação atingiu um patamar inimaginável, quase em escala fordista, que por vez acaba gerando novas imagens que alimentam e são retroalimentadas por sociedades espetaculares (DEBORD, 1997).

Nesse contexto, as obras de arte expostas nos museus e galerias se tornaram foco preferencial dos aparatos fotográficos que compõem os smartphones, uma característica marcante de sociedades 'massificadas' por práticas relativas às novas tecnologias da informação e da comunicação. Para muitos, parece não existir mais o tempo para a contemplação das obras e muito menos para a reflexão sobre as fotografias produzidas, visto que, depois de clicadas, as mesmas vão para a 'gaveta do esquecimento'. Em tal produção massiva, "A imagem deixa de ser o antigo objeto óptico do olhar para converter-se em imagerie” (FABRIS, 2009, p. 20I), uma percepção corroborada por Gilbert Durand, que nos ajuda a uma melhor compreensão acerca do consumo imagético desenfreado: 
É banal afirmar que nosso século $X X$ viu a construção de uma "civilização da imagem", graças aos gigantescos progressos técnicos de reprodução de imagens (fotografia, cinema, video-cassete, "imagens de síntese" etc.) e dos meios de transmiti-las (belinógrafo, televisão, telefax etc.). Pressente-se que essa inflação da produção e comércio de imagens [imagerie], (está) pronta para o consumo (DURAND, 200I, p. I).

Com isso, podemos dizer que o conceito de imagerie alinha-se também às discussões propostas por Guy Debord, na consideração de que "O mundo real se converte em simples imagens, estas simples imagens tornam-se seres reais e motivações eficientes típicas de um comportamento hipnótico" (DEBORD, 1997, p. 19). E nesse cenário, a falta de senso crítico para com a recepção da enxurrada imagética cotidiana, em especial a fotográfica, e a quase inexistência de um pensar reflexivo sobre o mundo que nos rodeia acarreta sérias consequências. Dentre elas, temos o afastamento de jovens escolares para com as experiências estéticas propostas pelo entorno. Ou seja, uma interação ativa e dinâmica que acontece num fluxo energético 'vivo', oposto à contemplação passiva (DEWEY, 2010).

E é o reconhecimento dessa distorção frente à produção, recepção e percepção das imagens que impulsionou a proposição do projeto de extensão "PhotoGraphein vai à Escola", em desenvolvimento desde 2012, no âmbito das ações extensionistas do PhotoGraphein - Núcleo de Pesquisa em Fotografia e Educação (UFPel/CNPq), sediado no Centro de Artes da Universidade Federal de Pelotas. As ações discutidas neste texto resultam de atividades do referido projeto de extensão, problematizando a construção de conhecimentos reflexivos em Artes Visuais no âmbito escolar.

No trabalho, são analisados resultados angariados nas edições de 2017 e 2018 , cujo públicoalvo foram estudantes dos anos finais do ensino fundamental de escolas públicas das cidades de Pelotas e Rio Grande, localizadas na região sul do Rio Grande do Sul. Os dados analisados são fruto de uma pesquisa de campo qualitativa, partindo de constatações, discussões e resultados imagéticos obtidos durante as práticas no espaço escolar. Isso, considerando o objetivo geral do "PhotoGraphein vai à Escola", o de proporcionar a estudantes da educação básica a construção de conhecimentos no campo de Artes Visuais, tendo como tema propulsor a fotografia.

No âmbito do projeto, a fotografia, suas práticas e produtos são considerados recursos amplificadores do olhar sensível e crítico sobre o cotidiano. Eles propiciam o estabelecimento de um espaço dialógico sobre os processos e resultados, como possibilidades de ver o cotidiano sob outra perspectiva, propondo o exercício do olhar crítico e a aproximação efetiva das pesquisas acadêmicas do contexto escolar. 


\section{A Fotografia enquanto linguagem não verbal}

Durante muitos séculos, as linguagens verbais "reinaram" absolutas nas tramas hegemônicas do conhecimento ocidental, alimentando a "luz da Ideia", lançando às trevas as imagens enquanto fontes de comunicação. Entretanto, o avanço tecnológico e a pluralidade de seus sistemas de signo, códigos e entrelaçamentos infindáveis impossibilitam a limitação da produção do conhecimento ao âmbito do verbal. Segundo Lucrecia Ferrara (2002), existem dois tipos de linguagem: a verbal e a não-verbal, sendo a primeira aquela que utiliza palavras escritas ou faladas nos processos comunicativos, diferente da não-verbal, que para ser concretizada utiliza signos visuais.

A crença na palavra foi tida durante séculos como o nível mais alto de intelectualidade, de modo hegemônico, e a consequência principal disso foi a de relegar a representação visual ao âmbito de um conhecimento secundário (FABRIS, 2009). Essa crença, que lançou às trevas as imagens enquanto fontes de comunicação, não se adequa mais à contemporaneidade, na qual cotidianamente utilizamos de linguagens não-verbais para interpretar e codificar o mundo e o contexto vivencial, visto que: "O mundo como texto, defendido até pouco tempo atrás por vertentes como o estruturalismo e o pósestruturalismo, está cedendo lugar ao mundo como imagem" (FABRIS, 2003, p. 32).

Se o texto verbal tem suas articulações e estruturações bem definidas pela linguística, a imagem possui suas constituições e organicidades internas, embora as artes visuais, ao contrário de outras manifestações, demoraram a firmar e teorizar suas estruturas (KANDINSKY, 200I). E isso se deve, muitas vezes, ao preconceito existente em seu próprio nicho, o que dificultou a sistematização de seus elementos, permitindo vislumbrá-la somente como composição formada de pontos, linhas, planos, cores, luz, formato, contrastes (LIMA, 1988). Esses elementos, significantes e constituintes dos conteúdos das Artes Visuais, podem estar inseridos em estilos, que produzem signos e fornecem-nos códigos de interpretação, porém não tão rígidos quanto os que a linguística impõe à interpretação textual-verbal.

Através das contribuições de Gilbert Durand (200I), entende-se o imaginário como o "museu" de todas as imagens primeiras, uma verdadeira "bacia semântica" que nos permite conhecer a essência que nos mobiliza, hoje e sempre. Assim considerando, a imagem fotográfica se destaca como um traço da percepção do real, também resultado da criação poética orquestrada pelo imaginário do fotógrafo, o qual "floresce das linguagens verbais e não-verbais que nos possibilitam a leitura de um mundo que emerge do conjunto de experiências sociais e individuais, da constelação de textos que viabilizam a circulação dos sentidos e dos saberes humanos" (BRANDÃO, 20I0, p. 14).

Isso na consideração da linguagem fotográfica como uma fonte de comunicação não-verbal, cujas imagens resultam de percepções subjetivas, nas quais "a imagem indiciária é dotada de um valor todo singular ou particular, pois determinado unicamente por seu referente e só por este: traço de 
um real" (DUBOIS, 1993, p. 45), sendo também uma criadora de novos universos pelos meandros do imaginário do fotógrafo (DURAND, 200I).

Frente à constatação da recepção acrítica e à banalização das imagens na contemporaneidade, considera-se de suma importância que os escolares desenvolvam um pensar sobre elas, atrelando tal pensamento ao seu cotidiano. Dessa forma, este artigo parte de discussões geradas no âmbito escolar, através das quais constatamos que estamos, em grande medida, reproduzindo padrões e comportamentos online inconscientemente, visto que:

A Pós-Modernidade é pontuada por discursos cada vez mais fragmentados. Convivemos num universo imageticamente poluído, com jornais, revistas, rádio, televisão, folhetos e outdoors de propaganda trazendo avalanches de mensagens e, mais do que nunca, é preciso ter critérios de avaliação que possibilitem uma seleção qualitativa das informações. No meio dessa gama de dados e da multiplicidade visual vigente, uma percepção apurada do mundo não é estimulada. Torna-se essencial, diante das imagens culturais e sociais que dominam o mundo, a construção de um pensamento crítico e transformador (TAVARES, 2010, p. 28).

É necessário esclarecer que não se objetiva condenar o uso da tecnologia no âmbito escolar, mas sim tem-se a pretensão de elucidar alguns questionamentos, propondo reflexões. Trata-se, portanto, de promover a 'inclusão digital crítica' dos escolares, através da qual possam compreender a importância do uso da tecnologia e ao mesmo tempo desenvolver a criticidade sobre ela. Isso porque, quando estamos anestesiados pela enorme gama de informações e imagens, muitas vezes "encontramonos distantes da apreensão sensível do mundo" (TAVARES, 2010, p. 29). Tais argumentos vão ao encontro ao termo cunhado por Rogéria Eler (2015) para definir aqueles que não pensam criticamente acerca dos usos e produtos tecnológicos, os "narcisos digitais".

Os "narcisos" contemporâneos não se manifestam nos moldes da cultura grega, que faz alusão ao mito de Narciso:

Na mitologia grega, Narciso era filho de Cefiso, um deus, e da ninfa Liríope. Segundo uma das versões mais conhecidas, como Narciso era um rapaz de beleza impressionante, a ninfa Eco se apaixonou perdidamente por ele. Eco era uma ninfa do bosque e fora castigada por Hera a apenas repetir o que os outros falassem, pois, sob as ordens de Zeus, distraia a deusa, enquanto ele buscava suas amantes. Contudo, Narciso rejeitou Eco, que definhou até seu corpo desaparecer, sobrando apenas a sua voz, que continuaria a se repetir eternamente. As outras ninfas, apoiadas por Nêmesis, deusa da vingança, amaldiçoaram Narciso e o fizeram se apaixonar perdidamente por sua própria imagem refletida nas águas. Já que não podia resistir a essa paixão, atirou-se nessas águas, para encontrar-se com seu reflexo e acabaria morrendo afogado. $O$ culto à imagem acabou por matar Narciso? (DUGNANI; CRUZ, 2007, p. 202).

Diferentemente dos gregos, os narcisos contemporâneos são fragmentados, e seus espelhos provocam a modificação e a multiplicação da identidade dos indivíduos num ciclo interminável (ELER, 2015). Essas pessoas podem ter suas identidades "diluídas" pelo mundo virtual, se "alimentando" cada 
vez mais do que ali encontram, das imagens e das redes sociais, sem desenvolver um pensar crítico acerca dos conteúdos consumidos e produzidos cotidianamente. Além disso, cabe destacar o consequente apagamento identitário e a ruptura do sentimento de pertencimento comunitário, visto que a identificação muitas vezes se dá com as comunidades virtuais, desconectadas do mundo real. Segundo Rogéria Eler (2015, p. 298):

(...) as interações digitais vivenciadas na internet funcionam como duplo do eu projetando ali uma ilusão biográfica. Esta ilusão cria e recria identidades, que falecem e nascem conforme as conquistas e sublimações que atendem ao projeto de resolver sua insatisfação, a não conquista de si mesmo. As referidas ações, de trânsitos de imagens, adentram uma esfera gigantesca de compartilhamentos numa hibridização de conexões humanas a partir da tecnologia, ganhando um aspecto de autorretratação em que os Narcisos customizam uma identidade visual híbrida e vivenciam experiências em outro corpo, a partir de avatares, por exemplo. Embora seja um corpo digital é a extensão de si, o duplo do eu, em movimento, o que proponho, a partir dessas metamorfoses, considerar o interator enquanto Narcisos digitais.

Para entendermos a realidade dos narcisos digitais, é necessário analisar o mito fundador de modo atento e reflexivo, percebendo que a questão narcísica está intimamente relacionada ao universo da arte, desde seus primórdios. Inclusive, Philippe Dubois expõe a conexão do mito com o surgimento da pintura, relacionando a figura de Narciso e o espectador diante de um quadro, explicando a relação que os une:

Se a imagem observada na fonte por Narciso é o seu próprio reflexo "pintado" e se o quadro, como a fonte, é também uma pintura - "reflexo, então o que reflete será sempre a imagem do espectador que a observa, que nela se observa. Sou, portanto, sempre eu que me vejo no quadro que olho. Sou (como) Narciso: acredito ver um outro, mas é sempre uma imagem de mim mesmo (DUBOIS, 1993, p. I43).

Em concordância com a discussão até aqui entabulada, propomos uma reflexão acerca da tecnologia, da produção e do consumo de imagens no cotidiano de jovens escolares, a fim de ressaltar a importância da formação dos indivíduos contemporâneos como espectadores emancipados (RANCIÈRE, 20I7). Para tanto, são analisados os resultados de atividades desenvolvidas no âmbito do projeto de extensão "PhotoGraphein vai à Escola", desenvolvido desde meados de 2012 com estudantes dos anos finais do ensino fundamental, em escolas públicas das cidades gaúchas de Pelotas e Rio Grande. O projeto tem a fotografia como "coluna vertebral" uma linguagem não-verbal, cujo exercício pode potencializar a imaginação e a expressão criadora, e a emancipação frente aos estereótipos socialmente consagrados. 


\section{Práticas Fotográficas estimuladoras do senso crítico no âmbito escolar}

As práticas iniciais do projeto priorizam a abordagem da fotografia artesanal, com base nos seus procedimentos analógicos. Isso envolve atividades de construção de câmeras pinhóle 'lata-desardinha' (Figura I), uma expressão peculiar que propicia a criação de imagens ao mesmo tempo análogas e imaginárias, que surgem da imprevisibilidade do equipamento (SIRTOLI; BRANDÃO, 20I8). Através de tal procedimento, fica explicitado o fenômeno físico-químico de formação das imagens, rompendo com a ideia de instantaneidade mecânica vinculada aos equipamentos digitais.

Figura I: Carine Rodriguez. Estrutura da câmera 'lata de sardinha', fotomontagem, 2012.

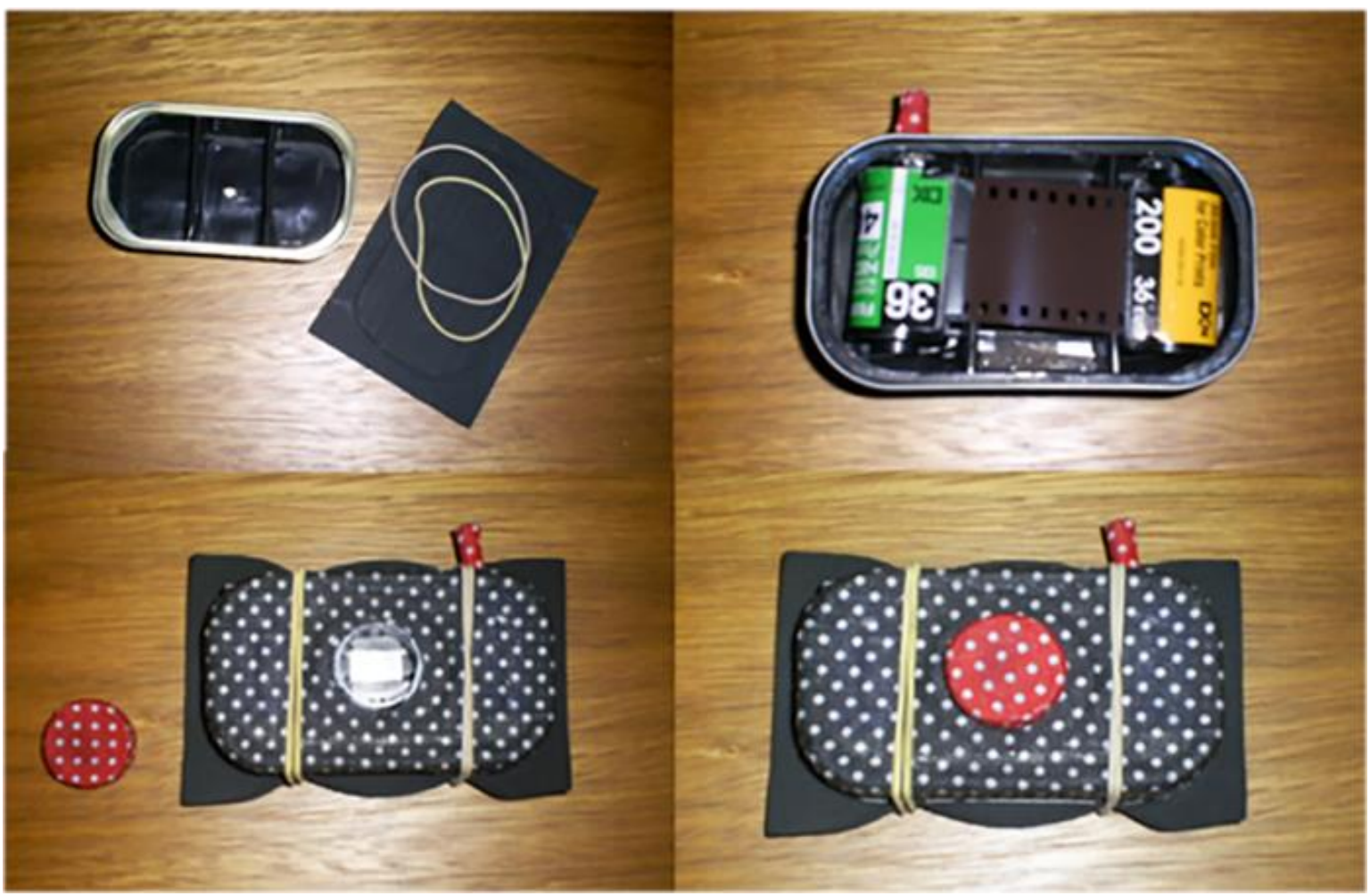

Fonte: Acervo do projeto, 2012.

As imagens da lata resultam de procedimentos artesanais, que dispensam o uso de câmera fotográfica convencional, o que desperta a curiosidade e aguça o raciocínio na identificação do fenômeno. Além das câmeras artesanais, também foram criadas grandes câmeras escuras com os escolares, mostrando, por meio da teoria e da prática, como se formam as imagens. Tais práticas possibilitam uma nova visão e compreensão não somente da fotografia e da formação das imagens, mas também uma nova visão de mundo. Esses procedimentos reiteram que:

Arte não é apenas básica, mas fundamental na educação de um país que se desenvolve. Arte não é enfeite. Arte é cognição, é profissão, é uma forma diferente 
da palavra para interpretar o mundo, a realidade, o imaginário, e é conteúdo. Como conteúdo, arte representa o melhor trabalho do ser humano. Arte é qualidade e exercita nossa habilidade de julgar e de formular significados que excedem nossa capacidade de dizer em palavras. E o limite da nossa consciência excede o limite de palavras (BARBOSA, 2014, p. 4).

Reconhecendo que, desde muito jovens, os escolares são estimulados, através das novas tecnologias da informação e da comunicação, a conviverem com um número absurdo de imagens que povoam as timelines, "a ideia não é desestimular a criança, já estimulada pela mídia, mas fazê-la refletir sobre a imagem" (BARBOSA, 1975, p. 92). Ao contrário, entendemos os novos contextos digitais e a intrínseca necessidade de estimular reflexões, problematizando os meios e os fundamentos de criação das imagens, em especial as fotográficas, visto que os aparatos tecnológicos democratizaram as câmeras fotográficas e seus usos. Somos conscientes também de que um número significativo dos novos "fotógrafos" desconhece o funcionamento dos equipamentos analógicos e os procedimentos de formação das imagens fotográficas.

Entabular conhecimentos acerca da formação das imagens é capaz de transformar a própria produção imagética em um 'dispositivo crítico', suscitando reflexões pertinentes acerca da própria realidade: "O dispositivo crítico visava assim a um efeito duplo: a tomada de consciência da realidade oculta e o sentimento de culpa em relação à realidade negada" (RANCIÈRE, 2017, p. 30). Portanto, tais discussões e práticas são fundamentais, visto que, sem a reflexão crítica, a produção e a leitura das imagens acabam sendo banalizadas, relegadas à condição de fruto do automatismo digital.

Atualmente, o projeto está centrado em duas escolas: a Escola Municipal de Ensino Fundamental Peixoto Primo (Rio Grande, RS) e a Escola Municipal de Ensino Fundamental Joaquim Nabuco (Pelotas, RS), a primeira localizada próxima da orla marítima do Balneário Cassino, e a outra num bairro periférico da cidade de Pelotas. Ou seja, lidamos com públicos que convivem em diferentes contextos, inclusive no que se refere ao meio ambiente.

Ultrapassada a etapa de reconhecimento dos recursos fotográficos, abordamos questões relativas ao ver e ao olhar, alternando encontros expositivo-dialogados e práticas com saídas de campo, visando o reconhecimento de cada contexto e suas especificidades. Com o objetivo de estimular um pensar crítico sobre a obviedade da visão, partimos do exemplo do fotógrafo cego Evgen Bavcar (1946), esloveno radicado em Paris que ficou cego em decorrência de dois acidentes de guerra, aos 12 anos de idade, cujo “(...) trabalho se estrutura a partir de uma busca de reconciliar o mundo visível ao invisível" (MAGALHÃES, 2004, p. 74).

Partimos da análise de algumas imagens de Bavcar (Figura 2), bem como da sua participação no documentário brasileiro "Janela da Alma” (2002), para abordar questões acerca do sentido da visão e da produção de imagens. Para muitos estudantes, foi uma surpresa conhecer um fotógrafo que produz imagens sem o auxílio da visão. Reconhecemos que, para o senso comum, a fotografia é tida como uma 
mimese da realidade, reproduzindo-a tal e qual, porém: "a foto é uma fina fatia de espaço bem como de tempo. Num mundo regido por imagens fotográficas, todas as margens ('enquadramento') parecem arbitrárias" (SONTAG, 2004, p. 33).

Figura 2: Evgen Bavcar. Arlequim, fotografia, data desconhecida

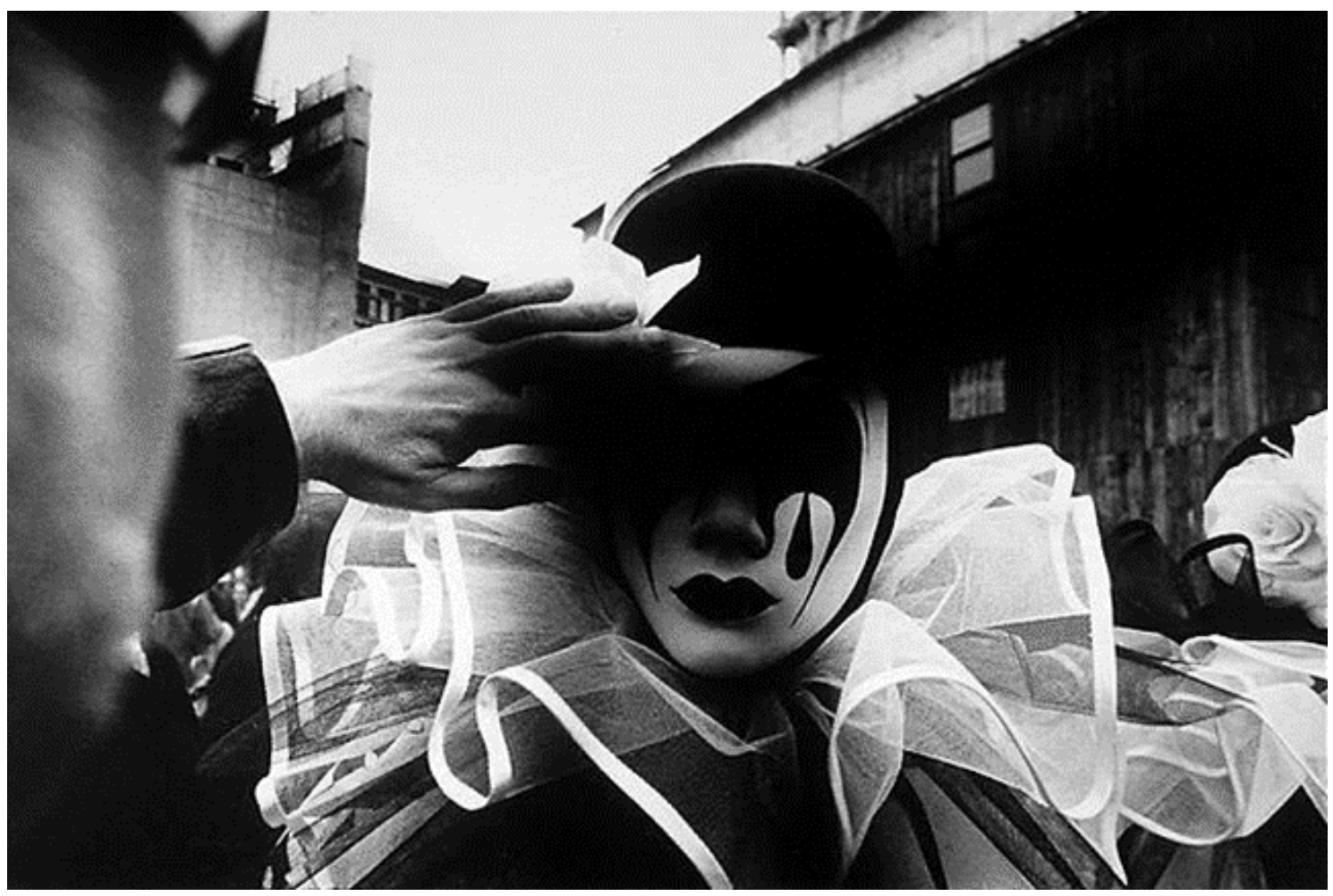

Fonte: https://versosemgotas.wordpress.com/20 I I/04/ /4/fotografia- I-evgen-bavcar/. Data de acesso: $22 / 10 / 2020$.

Na verdade, a imagem fotográfica é uma forma de mostrar a relação do 'eu-mundo', não apenas as relações que o fotógrafo possui para com o que está sendo retratado, mas também para com o espectador, assumindo múltiplos significados que são ressignificados a cada mirada. Sontag nos ajuda a compreender tal relação: "Como cada foto é um fragmento, seu peso moral e emocional depende do espaço em que ela se insere. Uma foto muda de acordo com o contexto em que é vista" (SONTAG, 2004, p. 122).

Além das questões próprias no que concerne à fotografia, foram apresentadas aos escolares as diferenças entre "ver" e "olhar", propostas por Márcia Tiburi. Para a filósofa, o "ver" está relacionado ao sentido prático da visão, enquanto o "olhar" requer lentidão e, principalmente, reflexão para acontecer (TIBURI, 2004). Podemos dizer então que na contemporaneidade, muitas pessoas conseguem ver, mas poucas realmente param para olhar. Tiburi complementa: 
A lentidão é do olhar, a rapidez é própria ao ver. O olhar é feito de mediações próprias à temporalidade. Ele sempre se dá no tempo, mesmo que nos remeta a um além do tempo. Ver, todavia, não nos dá a medida de nenhuma temporalidade, tal o modo instantâneo com que o realizamos. Ver não nos faz pensar, ver nos choca ou nem sequer nos atinge. (...) O olhar mostra que não é fácil ver e que é preciso ver, ainda que pareça impossível, pois no olhar o objeto visto aparece em seus estilhaços de ser e só com muito custo é que se recupera para ele a síntese que nos possibilita reconstruir o objeto. É como se depois de ver fosse necessário olhar, para então, novamente ver. Há, assim, uma dinâmica, um movimento - podemos dizer - um ritmo em um processo de olhar-ver (TIBURI, 2004, p.I).

Figura 3: Frame do documentário 'Janela da Alma' mostrando o processo fotográfico de Bavcar

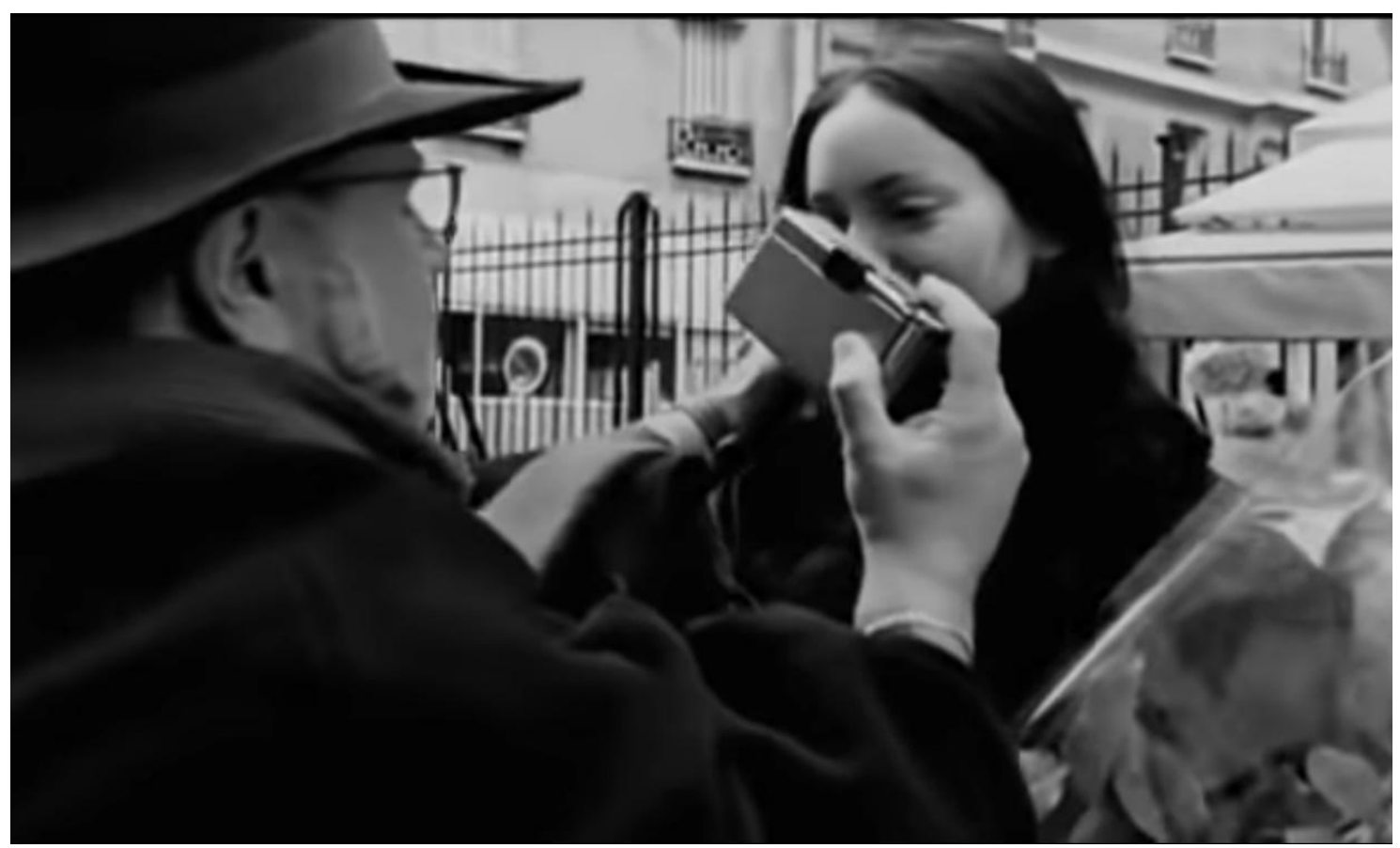

Fonte: Acervo do projeto, 2018.

Através do processo fotográfico de Evgen Bavcar (Figura 3), foi possível para os escolares transgredirem suas percepções preestabelecidas acerca da produção das imagens. Assim, logo no primeiro encontro com os escolares, estabeleceu-se o entendimento de que pessoas que não possuem o sentido da visão, como Bavcar, podem exercitar o "olhar" com o auxílio dos outros sentidos, o que exige tempo, pausa e reflexão para acontecer.

No documentário exibido, um comentário de Bavcar, em especial, chamou a atenção dos estudantes, quando ele declara que não necessita assistir à televisão com os olhos para compreender o que está lá, pois é sempre “mais do mesmo”. Ou seja, os jovens estudantes se surpreenderam com o fato de alguém que não enxerga ser capaz de perceber o seu entorno, talvez de forma mais profunda do que muitos dotados de visão. 
Após a discussão e problematização, os alunos foram direcionados ao pátio para a parte prática da atividade. Eles foram divididos em duplas, sendo ambos vendados (Figura 4). Enquanto um ficava com a câmera, o outro percorria o espaço utilizando os outros sentidos (principalmente a audição e o tato), com a intenção de que, após uma ambientação com a nova realidade, se encontrassem para a realização do registro fotográfico. A atividade promoveu uma aprendizagem significativa em grupo, evidenciada nos resultados e percepções comentadas por cada um.

Figura 4: Guilherme Susin Sirtoli. Fotografando de olhos vendados, fotografia, 2017

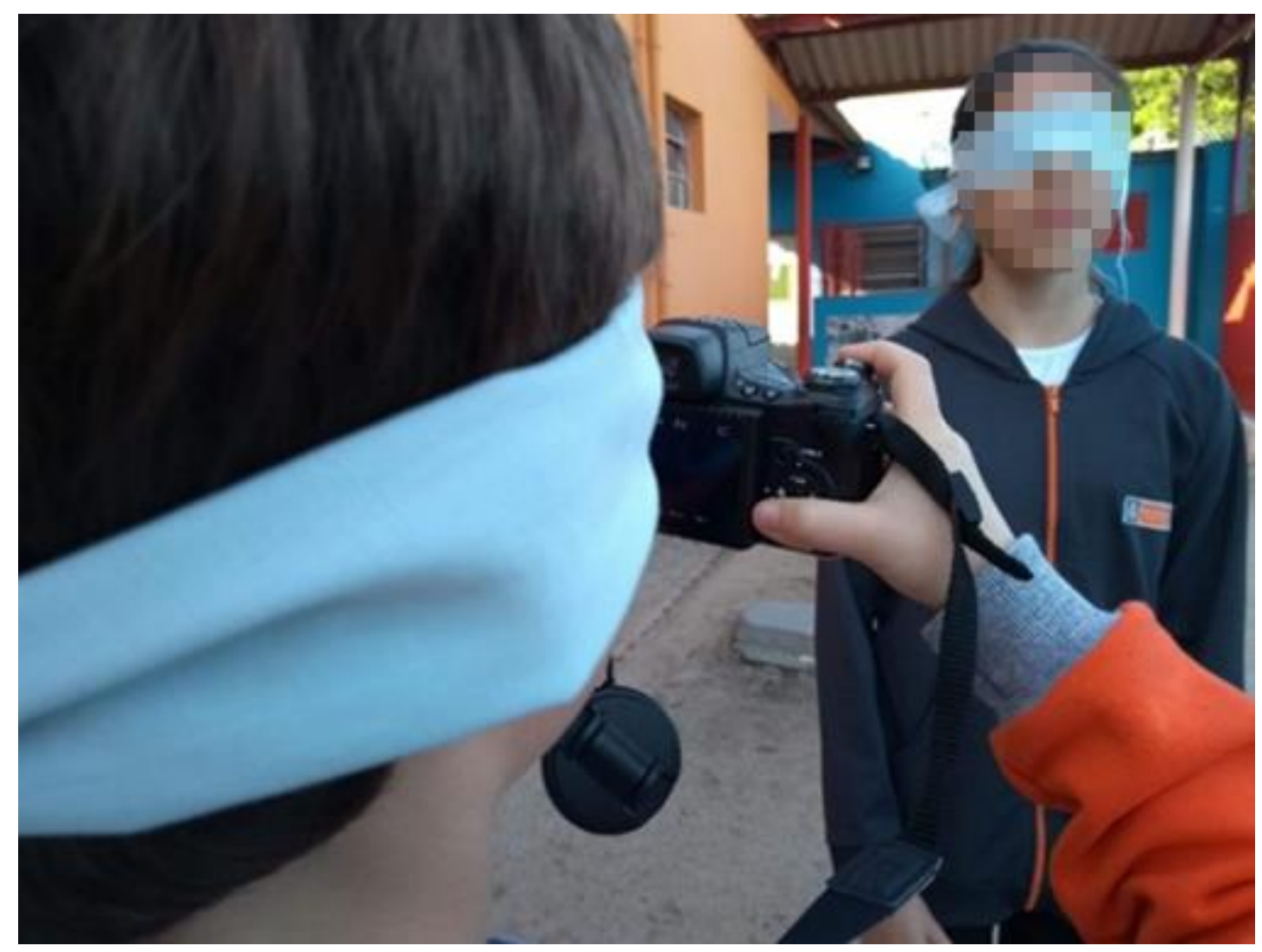

Fonte: Acervo do projeto, 2018.

Nos encontros subsequentes, foram discutidos os resultados fotográficos obtidos por cada um e a atividade em si. Para tanto, foram impressas as imagens produzidas, posteriormente analisadas enquanto forma e conteúdo. Nas discussões, os jovens escolares demonstraram um maior entendimento acerca das questões relativas ao ver e ao olhar e decidiram criar coletivamente um trabalho que evidenciasse as diferenças entre eles, algo que ficou explícito durante as análises: somos muito diferentes uns dos outros. Como síntese artística das discussões e descobertas/constatações foi criado um painel (Figura 5) com as imagens e intervenções em desenho e colagem, de modo autônomo 
e reflexivo, proposto pelos próprios escolares. E assim, foi possível perceber visualmente o quanto as atividades agregaram conhecimentos e ponderações pertinentes à realidade dos participantes.

Figura 5: Guilherme Susin Sirtoli. Ser diferente é normal, é legal, fotografia, 2017

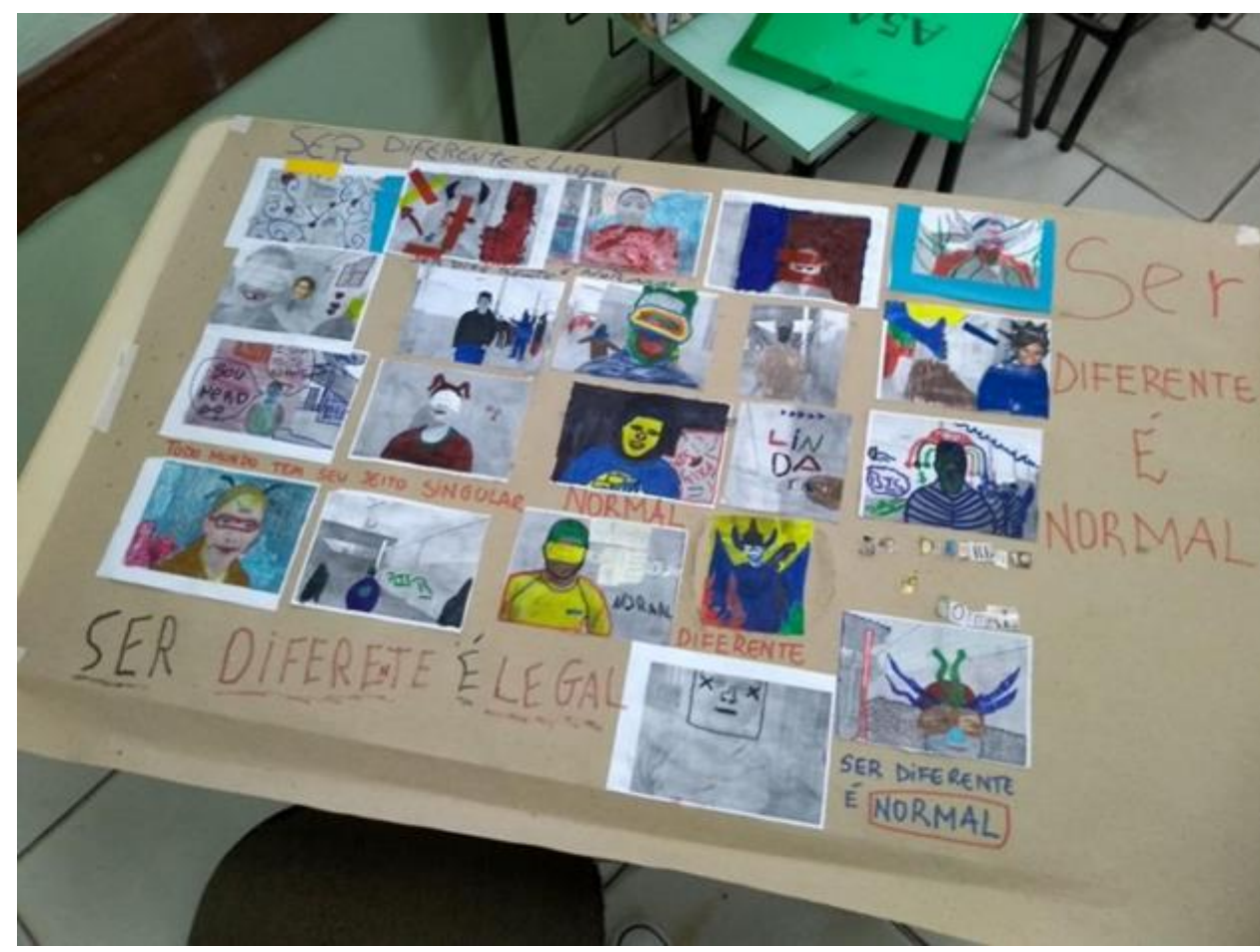

Fonte: Acervo do projeto. 2017.

Segundo uma aluna da EMEF Peixoto Primo: "Tirar uma fotografia com os olhos vendados foi uma experiência bastante diferente, consegui perceber a dificuldade em não usar a visão para fotografar e pude pensar melhor sobre as fotos que faço". A constatação nos aproxima de Rubem Alves e sua ideia sobre a Educação do Olhar: "Há muitas pessoas de visão perfeita que nada veem. O ato de ver não é coisa natural. Precisa ser aprendido. Quando a gente abre os olhos, abrem-se as janelas do corpo e o mundo aparece refletido dentro da gente" (ALVES, 20 I8, s/p).

Assim, consideramos que os participantes das atividades foram estimulados a um pensar mais crítico sobre a função do olhar, corroborando com a ideia de que "o olhar é a ruminação do ver: sua experiência alongada no tempo e no espaço e que, por isso, nos instaura em outra consistência de ser. Nossa cultura hipervisual dirige-se ao avanço das tecnologias do ver, mas não do olhar" (TIBURI, s/d, p. I), o que nos faz perceber a importância de discutir tais questões em sala de aula. Com o avanço da tecnologia e da imersão em uma cultura hipervisual, não estamos mais acostumados a pausar e refletir para analisar as imagens que nos intimam cotidianamente. Sendo assim, consideramos que as artes 
visuais e seus processos pedagógicos são fundamentais para nos distanciarmos criticamente da mecanicidade em que estamos imersos.

Tais percepções nos mostram que ao mesmo tempo em que os estudantes desenvolverem um olhar e senso crítico estético para com o cotidiano, os mesmos também desenvolvem um pensar crítico formador acerca da realidade. Isso, na consideração do papel relevante que as imagens desempenham no cotidiano contemporâneo, suprindo demandas das instituições com relação ao consumo consciente das imagens, e permitindo discussões facilitadoras da construção de um conhecimento teórico-prático em consonância com o real.

Tais questões foram evidenciadas nas declarações escritas pelos estudantes, em que expressaram suas percepções acerca das atividades desenvolvidas através do projeto de extensão. Um aluno do sexto ano da EMEF Peixoto Primo declarou: "Não sabia que pessoas cegas podiam fotografar, nunca parei pra pensar sobre isso, tenho um tio que nasceu cego e vou ensinar ele a tirar fotos também. A gente pode olhar sem precisar dos olhos pra isso". Esse depoimento apresenta um pensar além da própria produção de imagens, comprovando que os escolares puderam ampliar seu repertório imagético conhecendo o trabalho de Evgen Bavcar, e agregaram conhecimentos que são pertinentes à realidade de cada um.

Consideramos, como já declarado anteriormente, que a pausa para a contemplação nunca foi tão necessária para a ruptura da mecanização perceptiva do mundo. Como a arte é um reflexo da vida, é necessário entendermos que a "vida se dá em meio ambiente; não apenas nele, mas por causa dele, pela interação com ele" (DEWEY, 20I0, p. 74). Portanto, Dewey encaminha a compreensão de que a experiência tem uma extensão elástica, que não é delimitada por um final, ela repercute num continuum que exige dedicação, empenho, para acontecer. E podemos compreender melhor tal concepção através das ideias propostas por Nicholas Ferreira (201 I, p. I54):

Um exemplo bem singelo que podemos apresentar é o da criança que começa a sentir o mundo ao redor. Cada objeto, som, textura, etc., apresentam-se como um todo sem começo nem fim, mas um fluxo que é apreendido através de nossos sentidos em um movimento de estabelecer e expandir certos padrões em suas ações.

Por conta da experiência formadora desencadeada pela atividade, os escolares conseguiram não só perceber a importância da pausa reflexiva e da efetivação de um olhar mais lento sobre as imagens que consomem, quanto um pensar acerca da própria produção de imagens. Sabemos que o imediatismo e a falta de reflexão acerca do que os olhos enxergam provocam alienação, impedindo o fluxo ao qual se refere Ferreira.

Através das avaliações também foi possível percebermos o impacto da utilização de máquinas analógicas nas práticas: "Eu gostei muito dessa nova experiência porque sempre tirava foto e olhava 
para ver se ficava boa, mas com a câmera fotográfica (analógica) tive que tirar a foto com o pensamento para saber se ia ou não ficar boa" (Estudante da EMEF Joaquim Nabuco). Ou seja, através dessa opinião, confirmamos que a ruptura da instantaneidade no processo de elaboração da imagem, via equipamentos digitais, ativa o pensamento crítico, mesmo com o "fotógrafo" vendado.

A prática exigiu a percepção do outro através do toque na busca do melhor enquadramento, pois previamente sabiam que não poderiam simplesmente deletar o resultado, muito menos realizar várias imagens para selecionar a melhor. Entenderam também que existe um custo implicado na escolha, o que valoriza as escolhas. As ações viabilizaram a descoberta dos fenômenos envolvidos na formação de imagens de uma forma lúdica e sensível, levando ao desencadeamento de experiências formadoras entre os alunos, valorizando não só as imagens, mas, principalmente, o ensino escolar das Artes Visuais como oportunizador de experiências ativadoras da imaginação criativa.

É importante salientar que entendemos por experiência uma reação entre dois elementos que pode alterá-los e, consequentemente, modificar a realidade de ambos (WESTBROOK; TEIXEIRA, 2010). Sendo assim, quando existe uma dedicação para com as experiências, vivenciando-as em suas totalidades, possibilita-se uma mudança reflexiva, como nos aponta os autores que refletiram sobre $\circ$ trabalho de Dewey, Teixeira e Westbrook (2010, p. 34):

Qualquer experiência há de trazer esse resultado, inclusive as experiências humanas de reflexão e conhecimento. Com efeito, o fato de conhecer uma coisa importa em uma alteração simultânea no agente do conhecimento e na coisa conhecida. Essas duas existências se modificam, porque se modificaram as relações que existiam entre elas. A árvore que era apenas objeto de minha experiência visual, passa a existir de modo diverso, se entre mim e ela outras experiências se processarem, pelas quais eu a venha conhecer em outros aspectos: úteis, medicinais, de resistência, etc. Depois dessas experiências, eu e a árvore somos alguma coisa diferente do que éramos antes. Existimos de modo diverso um para o outro. Houve, por meio daquelas experiências, uma transformação que irá permitir alterar, sob certo aspecto, o mundo em que vivo.

Podemos articular o pensamento dos autores com o depoimento de uma aluna do quinto ano da EMEF Joaquim Nabuco, que comenta sobre os usos dos aparatos fotográficos analógicos e a surpresa que foi 'descobrir' tais mecanismos:

[...] acho que antigamente a gente tinha que cuidar mais das fotos que a gente tirava. Hoje todo mundo tira muitas fotos pelo celular e depois a gente nunca mais olha pra elas. Adorei saber sobre como eram as fotos antigamente, era sempre uma surpresa ver como elas ficavam.

Assim, julgamos que a pausa e a reflexão provocadas pelas ações extensionistas foram de suma importância para uma real vivência do processo de registrar e ser registrado através das lentes de uma câmera fotográfica. Nesse sentido, consideramos que o ensino da arte, em especial as práticas que privilegiam a educação do olhar, pode propiciar aos escolares uma nova forma de ver e pensar o mundo 
ao redor. Tal educação do olhar é fundamental para quebrar a automaticidade e a passividade em meio ao dinamismo do mundo contemporâneo, no qual as imagens acabam se tornando mercadorias. devido pensar sobre as imagens "denuncia a inversão da vida que consiste em ser consumidor passivo de mercadorias que são imagens e de imagens que são mercadorias" (RANCIĖRE, 2017, p. 87).

$\mathrm{Na}$ educação básica, quando somos estimulados (ou não) a experimentar o mundo ao nosso redor, pode ter início a descoberta da complexidade do real, estabelecendo uma relação de pertencimento e responsabilidade social com o contexto vivencial, pois pelo fato de o "mundo real, este em que vivemos, ser uma combinação de movimento e culminação, de rupturas e reencontros, a experiência do ser vivo é passível de uma qualidade estética" (DEWEY, 2010, p. 80).

Por outro lado, se não pensamos, não agimos, não entramos em movimento para com o real, e assim nos tornamos passivos, anestesiados e cada vez mais distantes da experiência propriamente dita. Quando não refletimos minimamente sobre aquilo que vemos, estamos nos sujeitando à dominação e à alienação. Nesse sentido, cabe destacar que somente o encaminhamento teórico de tais questões pode não atingir o público escolar de modo elucidativo. Para uma compreensão mais efetiva, a vivência de situações que desloquem os estudantes da posição de passividade possibilita um estranhamento que pode ser transformador das percepções do real, como têm comprovado as práticas do projeto.

Sabedores de que a realidade está aberta a diferentes interpretações, entendemos necessária a formação de espectadores emancipados (RANCIÈRE, 2017). Através das artes visuais e de suas práticas pedagógicas, no caso aqui discutido a fotográfica, estimulamos o olhar, o representar e a criação de outras realidades, considerando que:

A emancipação, por sua vez, começa quando se questiona a oposição entre olhar e agir, quando se compreende que as evidências que assim estruturam as relações do dizer, do ver e do fazer pertencem à estrutura da dominação e da sujeição. Começa quando se compreende que olhar é também uma ação que confirma ou transforma essa distribuição das posições. $O$ espectador também age, tal como o aluno ou o intelectual. Ele observa, seleciona, compara, interpreta. Relaciona o que vê com muitas outras coisas que viu em outras cenas, em outros tipos de lugares. Compõe seu próprio poema com os elementos do poema que tem diante de si (RANCIĖRE, 2017, p. 17).

Dessa forma, constatamos que as práticas extensionistas colaboraram para uma aprendizagem significativa dos envolvidos, o que foi corroborado através dos trabalhos produzidos e dos depoimentos. Por meio do aparato fotográfico, os estudantes puderam se "entregar" às experiências propostas pelo entorno, sendo estimulados no desenvolvimento de olhares críticos e reflexivos para com as imagens e o mundo ao redor, confirmando a relevância dos conceitos de emancipação do 
pensamento, nomeado por Rancière (2017), e o de experiência formadora, proposto por Dewey (2010).

\section{Considerações Finais}

Através da análise e reflexão desenvolvidas, constata-se a significativa contribuição dos processos pedagógicos problematizados para reflexões acerca da participação de todos na geração e no incremento, muitas vezes de modo acrítico, de sociedades cada vez mais imagéticas. Fazeres que exploram a fotografia, suas práticas e produtos, situada como uma linguagem não-verbal, reafirmam a importância do ensino da arte no contexto escolar, para visibilizar as inter-relações entre Arte, Sociedade e Tecnologia. Com as práticas fotográficas, foi possível estabelecer relações e aprendizados que alteraram positivamente a forma como os jovens escolares decodificam e percebem os símbolos presentes no mundo ao seu redor.

O andamento das atividades do projeto de extensão "PhotoGraphein vai à Escola" e a problematização dos seus resultados revelam como os seus participantes desenvolveram saberes e pensamentos contundentes acerca das relações entre as sociedades contemporâneas e as diferentes imagens que permeiam o âmbito pessoal e comunitário das populações. Através das discussões e das atividades práticas, foi possível promover nas escolas reflexões teóricas e estéticas acerca de transformações que nos classificam como uma "civilização da imagem”, principalmente em função da difusão da tecnologia digital, mediadora determinante para os novos modos comunicacionais. Mais do que isso, foi aberto um espaço para que fossem problematizadas as relações particulares de cada um com as suas cidades e o mundo que os rodeia, expondo as diferenças entre as vivências dos sujeitos e suas relações com o espaço urbano.

A falta de uma problematização acerca das imagens gera $\circ$ afastamento das experiências formadoras possibilitadas pelo entorno, bem como a alienação. Constatamos que somente após a vivência de situações específicas é possível a efetivação de experiências formadoras, cujas reflexões surgem em função da utilização da fotografia como um potente meio propulsor do olhar crítico. $O$ exercício de ler o mundo nas entrelinhas dos signos permitiu aos participantes ver, observar, selecionar, descobrir, revelar e revelar-se, transgredindo os limites da presença e da ausência, alargando a capacidade humana de simbolização, e apreendendo a fotografia enquanto um suporte das subjetividades e manifestação dos imaginários.

Analisando tais questões, percebemos que foi elaborado um entendimento sobre o relacionamento da sociedade com as imagens que produz, transgredindo as percepções socialmente consagradas e estabelecendo formas criativas de comunicação. Essas formas comunicativas se manifestam como possibilidades de processos reflexivos, filosóficos e artísticos acerca da compreensão 
de nós mesmos e do mundo. A importância dessas práticas repousa na potencialidade oferecida para o desenvolvimento de múltiplas aprendizagens decorrentes da reflexão crítica sobre as próprias vivências, possibilitando a transformação do vivido em experiências formadoras para todos os envolvidos.

\section{Referências}

ALVES, R. Sem a educação das sensibilidades, todas as habilidades são tolas e sem sentido. Revista Pazes, 2 I ago. 2018. Disponível em: https://www.revistapazes.com/educacaosensibilidadesrubemalves/. Acesso em: 24 ago. 2021.

BARBOSA, A. M. A Imagem no Ensino da Arte. São Paulo: Perspectiva, 2014.

BARBOSA, A. M. Teoria e prática da Educação Artística. São Paulo: Cultrix, 1975.

BRANDÃO, C. M. M. B. Graphias do tempo em mim. In: BRANDÃO, C. M. M.; SCHMIDT, E. B.; LENZI, T. de J. M. Sob o signo da cegueira: foto-graphando o cotidiano. Pelotas: Editora UFPel, 20I0. p.I0-2I.

DEBORD, G. A Sociedade do Espetáculo. Rio de Janeiro: Contraponto, 1997.

DEWEY, J. Arte como experiência. São Paulo: Martins Fontes, 2010.

DUBOIS, P. O Ato Fotográfico e outros ensaios. Campinas: Papyrus, 1993.

DUGNANI, P.; CRUZ, L. A. Mitologia e pós-modernidade: Proteu, Argos e Narciso - Os mitos e seus reflexos na sociedade. Anuário de Produção Acadêmica Docente, Sistema Anhanguera de Revistas Eletrônicas - SARE, v. I, n. I, p. 20I-206, out. 2007. Disponível em:

https://repositorio.pgsskroton.com/handle/I23456789//309 Acesso em: I2//2/2019.

DURAND, G. O imaginário: ensaio acerca das ciências e da filosofia da imagem. Rio de Janeiro: DIFEL, 200 I.

ELER, R. Mestiçagem em arte: narcisos digitais e as narrativas transmídia. In: GONÇALVES, Maria Gorete Dadato; REBOUÇAS, Moema Martins. (orgs.). Educação em Arte na

Contemporaneidade. Vitória: EDUFES, 2015. p.296-305.

FABRIS, A. A imagem hoje: entre passado e presente. In: DOMINGUES, Diana (org.). Arte, Ciência e Tecnologia: Passado, presente e futuro. São Paulo: UNESP, 2009. p. 20I-206.

FABRIS, A. Discutindo a Imagem Fotográfica. Domínios da Imagem, v. 2, n. 3, p. 12-23, jan./jul. 2003. Disponível em: https://www.uel.br/revistas/uel/index.php/dominiosdaimagem/article/view// 9252 Acesso em: 12/12/2019.

FERRARA, L. D’A. Leitura sem palavras. 4. ed. São Paulo: Ática, 2002. 78p.

FERREIRA, N. G. M. L. O papel da experiência na filosofia de John Dewey. In: ENCONTRO DE PESQUISA NA GRADUAÇÃO EM FILOSOFIA DA UNESP, 6., 20II, São Paulo. Anais [...] São Paulo, v.4. n.2. p.I47-I56, 20I I. Disponível em: 
https://www.marilia.unesp.br/Home/RevistasEletronicas/FILOGENESE/nicholasminotti.pdf Acesso em: 12/12/2019.

HAN, B. No enxame: perspectivas do digital. Petrópolis: Vozes, 2018.

JANELA DA ALMA. Direção de João Jardim e Walter Carvalho. Produção de Flávio R. Tambellini. Rio de Janeiro: Copacabana Filmes, 2002. I DVD (73min), son., color.

KANDINSKY, W. Ponto e linha sobre plano: contribuição à análise dos elementos da pintura. São Paulo: Martins Fontes, 200I.

LIMA, I. A Fotografia e a sua linguagem. Rio de Janeiro: Espaço e Tempo, 1988. I19p.

MAGALHÃES, F. O corpo performático de Evgen Bavcar. Revista Educação PUC, Campinas, v.I, n. 16, p.73-78, 2004. Disponível em: https://periodicos.puc-

campinas.edu.br/seer/index.php/reveducacao/article/view/287 Acesso em: 12/12/2019.

RANCIÈRE, J. O espectador emancipado. São Paulo: WMF Martins Fontes, 2017.

SIRTOLI, G. S.; BRANDÃO, C. M. M. O olhar fotográfico como potência crítica na sala de aula. In: MIGLIORINI, Jeanine Mafra (org.). Reflexões sobre a Arte e seu Ensino. v.I. Ponta Grossa: Atena, 2018. p.288-298.

SONTAG, S. Ensaios sobre fotografia. São Paulo: Companhia das Letras, 2004.

TAVARES, C. M. S. Olhar que (es)colhe frutos. In: BRANDÃO, C. M. M.; SCHMIDT, E. B.; LENZI, T. de J. M. Sob o signo da cegueira: foto-graphando o cotidiano. Pelotas: Editora UFPel, 20I0. p.2I 32.

TIBURI, M. Aprender a ver é descobrir o olhar. Jornal do Margs, 103 ed. set./out. 2004. Disponível em: http://www.marciatiburi.com.br/textos/quadro_aprender.htm. Acesso em: 0l out. 2020.

WESTBROOK, R. B.; TEIXEIRA, A. John Dewey: Coleção Educadores (MEC). Recife: Fundação Joaquim Nabuco; Editora Massangana, 2010. Disponível em: http://www.dominiopublico.gov.br/download/texto/me4677.pdf. Acesso em: 01 out. 2020.

Recebido em: 03 de março de 2021.

Versão corrigida recebida em: 27 de agosto de 202I.

Aceito em: 27 de setembro de 2021 .

Publicado online em: 25 de fevereiro de 2022.

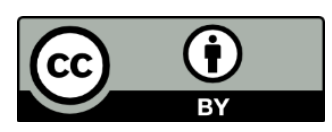

